\title{
Characterization of a complex context containing mecA but lacking genes encoding cassette chromosome recombinases in Staphylococcus haemolyticus
}

Zhiyong Zong ${ }^{1,2}$

\begin{abstract}
Background: Methicillin resistance determinant mecA is generally transferred by SCCmec elements. However, the mecA gene might not be carried by a SCCmec in a Staphylococcus haemolyticus clinical isolate, WCH1, as no cassette chromosome recombinase genes were detected. Therefore, the genetic context of mecA in WCH1 was investigated.

Results: A 40-kb region containing mecA was obtained from WCH1, bounded by orfX at one end and several orfs of $\mathrm{S}$. haemolyticus core chromosome at the other. This $40-\mathrm{kb}$ region was very complex in structure with multiple genetic components that appeared to have different origins. For instance, the 3.7-kb structure adjacent to orf was almost identical to that on the chromosome of Staphylococcus epidermidis RP62a but was absent from S. haemolyticus JCSC1435. Terminal inverted repeats of SCC were found but no ccr genes could be detected. mecA was bracketed by two copies of IS431, which was flanked by 8-bp direct target repeat sequence (DR).

Conclusions: The presence of 8-bp DR suggests that the two copies of IS431 might have formed a composite transposon for mobilizing mecA. This finding is of significance as multiple copies of IS431 are commonly present in the contexts of mecA, which might have the potential to form various composite transposons that could mediate the mobilization of mecA. This study also provides an explanation for the absence of $c c r$ in some staphylococci isolates carrying mecA.
\end{abstract}

\section{Background}

Methicillin-resistant staphylococci represent a great challenge for treatment and public health. In staphylococci, methicillin resistance is mainly due to the expression of the mecA gene, which specifies penicillin binding protein $2 \mathrm{a}$ (PBP2a), a transpeptidase with a low affinity for $\beta$-lactams $[1,2]$. mec $A$ is carried by a mobile genetic element (MGE) termed the staphylococcal cassette chromosome mec (SCCmec) [2,3]. Generally, SCCmec contains two essential components, i.e. the mec gene complex and the $c c r$ gene complex. The mec gene complex consists of mecA, the regulatory genes and associated insertion sequences and has been classified into six different classes, i.e. A, B, C1,

\footnotetext{
Correspondence: zongzhiy@scu.edu.cn

${ }^{1}$ Center of Infectious Diseases, West China Hospital, Sichuan University, Guoxuexiang 37, Chengdu 610041, China

${ }^{2}$ State Key Laboratory of Biotherapy, Sichuan University, Chengdu, China

C2, D and E. Cassette chromosome recombinase ( $c c r$ ) genes ( $c r C$ or the pair of $c r r A$ and $c c r B$ ) encode recombinases mediating integration and excision of SCCmec into and from the chromosome [2,3]. The $c c r$ gene(s) and surrounding genes form the $c c r$ gene complex.

A Staphylococcus haemolyticus clinical isolate, $\mathrm{WCH} 1$, was found carrying $m e c A$ but no $c c r$ genes. Although clinical isolates of $S$. haemolyticus containing mecA but lacking $c c r$ genes have been reported previously [4-6], information about the detailed contexts of mecA is largely absent. The genetic context of mecA in WCH1 was therefore investigated using long-range PCR, PCR mapping, inverse PCR and sequencing as described previously [7].

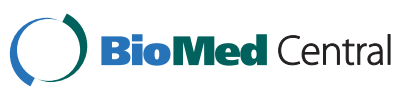




\section{Results and discussion}

The minimum inhibitory concentration (MIC) of cefoxitin against WCH1 was $128 \mu \mathrm{g} / \mathrm{ml}$. A 40-kb region containing $m e c A$ was obtained from WCH1, abutting orfX at one end and seven orfs designated orf39 to orf44 here (Table 1), which were also present in the oriC environ on the chromosome of the completely-sequenced S. haemolyticus strain JCSC1435 (GenBank accession no. AP006716) [8], at the other (Figure 1). The partial sequence of orfX obtained was $99 \%$ identical to that of S. haemolyticus JCSC1435. orf39 to orf44 were identical to the counterparts of S. haemolyticus JCSC1435 and were not part of any known mobile genetic elements (MGE), confirming that these orfs indeed belonged to the core chromosome of S. haemolyticus.

\section{mecA is bracketed by two copies of IS431 flanking by an 8-bp direct repeat sequence}

WCH1 had a class $\mathrm{C} 1 \mathrm{mec}$ gene complex composed of $m e c A$, mecR1 1 truncated by the insertion of the insertion sequence IS431, several other genes and another copy of IS431 downstream of mecA with the two copies of IS431 at the same orientation (Figure 1). The class C1 mec gene complex is also present in SCCmec types VII and X of Staphylococcus aureus and several unnamed types of SCCmec in coagulase-negative staphylococci (CoNS) [9].

An 8-bp identical sequence (CTTTTTGC; Figure 1) was identified flanking the two copies of IS431. The 8bp DR was part of the spacer sequence between arsR (encoding an arsenical resistance operon repressor) and $\operatorname{cop} A$ (encoding a copper-exporting ATPase). The presence of a direct repeat (DR) suggested that the two copies of IS431 might have formed a composite transposon with the potential to mediate the mobilization of mecA into different genomic locations. This mecA-carrying IS431-formed composite transposon was designated Tn6191 according to the transposon database (www.ucl. ac.uk/eastman/tn/). Composite transposons formed by IS431 generating 8-bp AT-rich DR on insertion have been seen before, such as Tn6072 carrying $\operatorname{crC} C$ and the aminoglycoside resistance determinant $a a c A$ found in a ST239 S. aureus [10]. Two copies of IS431 have also been found to mediate the transposition of plasmids pUB110 encoding bleomycin resistance [11] and pT181 encoding tetracycline and mercury resistance [12]. However, Tn6072 and other IS431-formed composite transposons do not contain mecA. IS431 is widely distributed in Staphylococcus epidermidis, S. haemolyticus and methicillin-resistant S. aureus (MRSA) [13] and appears to play a vital role in generating mosaicism in the genetic contexts of $m e c A$. The insertion of IS431 and homologous recombination between different copies of IS431 can result in acquisition, loss and re- arrangements of genetic components [14,15]. Therefore, IS431 apparently serves as the "adapters" allowing genetic components to be linked and clustered together to form complicated genetic contexts of mecA.

In GenBank and literature, e.g. [3], there are many cases in which mecA is bracketed by two copies of IS431, either at the same or opposite orientations, i.e. the class $\mathrm{C} 1$ or C2 mec complex. In these cases, two copies of IS431 have the potential to form a composite transposon mediating the mobilization of mecA but no 8-bp DR could be identified flanking the class $\mathrm{C} 1$ or $\mathrm{C} 2$ mec complexes. This suggests that the two copies of IS431 might have inserted in tandem rather than mobilize together as a unit. Alternatively, IS431 might behave likes IS26 [16], an insertion sequence also of the IS6 family, that could lead to adjacent deletions, leaving no DR.

No $c c r$ genes could be identified in this large region containing mecA. In the 1970 s and 1980s, it was found that methicillin resistance could be transferred by phages [17-21] in experimental conditions and could be also carried by a transposon, Tn4291, located on a naturally occurring plasmid, pI524 [21]. However, these studies were carried out before the identification of $m e c A$ and no sequence information was available for the phages carrying methicillin resistance, Tn4291 and pI524. It remains unclear whether methicillin resistance in these experiments was due to the expression of $\operatorname{mec} A$. In particular, Tn4291 mediated resistance to methicillin but not to penicillin, raising the possibility that the methicillin resistance determinant carried by Tn4291 was actually not mecA. mecA is usually transferred by SCCmec, but mecA existed in the absence of any known types of $c c r$ genes have been found in both MRSA and CoNS previously. In particular, no known ccr genes were detected for an half of methicillin-resistant S. haemolyticus isolates from a hospital in Tunisia [22], suggesting that elements carrying $m e c A$ but lacking $c c r$ genes might be common in $S$. haemolyticus. However, the detailed genetic context of $m e c A$ were not characterized in these cases and therefore the exact reasons for the absence of $c c r$ genes remain unclear [2]. The present study provides a detailed example that mecA was in a context without $c c r$ genes and might be able to be transferred by a MGE other than SCCmec.

\section{A complex SCC-like remnant containing components with various origins}

This 40-kb region between orfX and orf39 contained five copies of IS431 (designated IS431-1 to -5 from upstream of to downstream of $m e c A$, respectively) and three terminal inverted repeats (IR) of SCC elements (Figure 1). An IR was in the orfX, designated IR1 here. The second IR another was located between the lipoprotein-encoding gene, lip, and a putative Acyl-CoA acyltransferase-encoding gene, acf, designated IR2 here. The third IR was adjacent 
Table 1 Genes and MGE in the genetic context of mecA in WCH1

\begin{tabular}{|c|c|c|c|}
\hline Gene or MGE & Position $^{a}$ & Product & $\begin{array}{l}\text { Closest match }{ }^{b, c} \\
\text { Identity, species strain }\end{array}$ \\
\hline orfx & $1-316$ & Hypothetical protein & 99\%, S. haemolyticus JCSC1435 \\
\hline$A D P$ & $445-1431$ & ADP-ribosylglycohydrolase & 99\%, S. epidermidis RP62a (locus SERP2218) \\
\hline perM & $1450-2784$ & $\begin{array}{l}\text { Cytosine/purines, uracil, thiamine, } \\
\text { allantoin permease family protein }\end{array}$ & 99\%, S. epidermidis RP62a (locus SERP2217) \\
\hline$r b k \Delta^{d}$ & $2781-3719$ & Ribokinase & 99\%, S. epidermidis RP62a (locus SERP2216) \\
\hline 15431 & $3701-4401$ & 15431 & \\
\hline merR & $4888-5235$ & Transcriptional regulator of the merR family & $\begin{array}{l}\text { 100\%, type IX SCCmec of S. aureus JCSC6943 } \\
\text { and S. haemolyticus JCSC1435 (locus SH0094) }\end{array}$ \\
\hline this & 5313-5996 & ThiJ/Pfpl family protein & $\begin{array}{l}\text { 100\%, type IX SCCmec of S. aureus JCSC6943 } \\
\text { and S. haemolyticus JCSC1435 (locus SH0095) }\end{array}$ \\
\hline orf8 & $6018-6683$ & $\begin{array}{l}\text { NAD dependent epimerase/ } \\
\text { dehydratase family protein }\end{array}$ & $\begin{array}{l}\text { 100\%, type IX SCCmec of S. aureus JCSC6943, } \\
\text { type X SCCmec of S. aureus JCSC6945 } \\
\text { and S. haemolyticus JCSC1435 (locus SH0095) }\end{array}$ \\
\hline orf9 & $6687-7691$ & $\begin{array}{l}\text { Oxidoreductase, zinc-binding } \\
\text { dehydrogenase family protein }\end{array}$ & $\begin{array}{l}\text { 100\%, type IX SCCmec of S. aureus JCSC6943 } \\
\text { and S. haemolyticus JCSC1435 (locus SH0097) }\end{array}$ \\
\hline orf10 & $7700-8065$ & $\begin{array}{l}\text { Hypothetical protein of the COG4270 } \\
\text { superfamily, predicted membrane protein }\end{array}$ & $\begin{array}{l}\text { 100\%, type IX SCCmec of S. aureus JCSC6943, } \\
\text { type X SCCmec of S. aureus JCSC6945 } \\
\text { and S. haemolyticus JCSC1435 (locus SH0098) }\end{array}$ \\
\hline$c a d D$ & $8601-9218$ & Cadmium binding protein & $\begin{array}{l}\text { 100\%, type IX SCCmec of S. aureus JCSC6943 } \\
\text { and S. haemolyticus JCSC1435 (locus SH0099) }\end{array}$ \\
\hline $\operatorname{cad} X$ & $9237-9578$ & Cadmium resistant accessory protein & $\begin{array}{l}\text { 100\%, type IX SCCmec of S. aureus JCSC6943 } \\
\text { and S. haemolyticus JCSC1435 (locus SH0100) }\end{array}$ \\
\hline $\operatorname{arsC}$ & 9999-9598 & Arsenate reductase & $\begin{array}{l}\text { 100\%, type IX SCCmec of S. aureus JCSC6943 } \\
\text { and S. haemolyticus JCSC1435 (locus SH0101) }\end{array}$ \\
\hline $\operatorname{ars} B$ & $11306-10017$ & Arsenical pump membrane protein & $\begin{array}{l}\text { 99\%, type IX SCCmec of S. aureus JCSC6943 } \\
\text { and S. haemolyticus JCSC1435 (locus SH0102) }\end{array}$ \\
\hline $\operatorname{ars} R$ & $11623-11302$ & Arsenical resistance operon repressor & $\begin{array}{l}\text { 100\%, type IX SCCmec of S. aureus JCSC6943, } \\
\text { type X SCCmec of S. aureus JCSC6945 } \\
\text { and S. haemolyticus JCSC1435 (locus SH0103) }\end{array}$ \\
\hline 15431 & $11697-12486$ & 15431 & \\
\hline $\operatorname{mec} R \Delta$ & $12503-12487$ & Signal transducer protein & \\
\hline mecA & $12603-14609$ & Penicillin binding protein $2 a$ & \\
\hline orf19 & $15083-14655$ & Hypothetical protein & \\
\hline maoC & $15923-15180$ & Putative acyl dehydratase maoc & \\
\hline orf21 & $17208-16840$ & Putative HMG-CoA synthase (partial) & \\
\hline IS431 & 17209-17998 & IS431 & \\
\hline $\operatorname{cop} A$ & $18241-20262$ & Copper-transporting atpase & 99\%, type X SCCmec of S. aureus JCSC6945. \\
\hline orf24 & $20277-21710$ & Putative multicopper oxidases & $\begin{array}{l}\text { 99\%, S. haemolyticus JCSC1435 } \\
\text { (locus SH0106) }\end{array}$ \\
\hline lip & $21730-22212$ & Lipoprotein & 99\%, S. aureus JCSC6943 \\
\hline acf & $22588-23073$ & Putative Acyl-CoA acyltransferase & $\begin{array}{l}\text { 97\%, S. haemolyticus JCSC1435 } \\
\text { (locus SH0117) }\end{array}$ \\
\hline$h s d R$ & $23254-23667$ & Type I restriction endonuclease, $\mathrm{HsdR}$ & $\begin{array}{l}\text { 97\%, S. haemolyticus JCSC1435 } \\
\text { (locus SH0118) }\end{array}$ \\
\hline putP & $25274-23736$ & $\begin{array}{l}\text { Sodium/proline symporter } \\
\text { (High affinity proline permease) }\end{array}$ & $\begin{array}{l}\text { 78\%, S. saprophyticus ATCC } 15305 \\
\text { (locus SSP0399) }\end{array}$ \\
\hline IS431 & $26462-27184$ & IS431, truncated & \\
\hline$F A D$ & $27261-28382$ & $\begin{array}{l}\text { FAD-dependent pyridine nucleotide- } \\
\text { disulphide oxidoreductase }\end{array}$ & $66 \%$, a few S. aureus strains, e.g. COL \\
\hline
\end{tabular}


Table 1 Genes and MGE in the genetic context of mecA in WCH1 (Continued)

\begin{tabular}{|c|c|c|c|}
\hline$f e o B$ & $28376-29272$ & FeoB family ferrous iron transporter & $\begin{array}{l}\text { 68\% (partially, from position } 28804 \text { to 29216), } \\
\text { S. carnosus TM300 }\end{array}$ \\
\hline orf31 & 29337-29717 & Putative transmembrane protein & $\begin{array}{l}\text { 73\% (partially, from position } 29438 \text { to 29618), } \\
\text { S. aureus MSHR1132 }\end{array}$ \\
\hline IS431 $\Delta^{\mathrm{e}}$ & $30690-29891$ & $\begin{array}{l}\text { IS431, incomplete due to internal } \\
\text { termination }\end{array}$ & \\
\hline orf32 & $31660-33822$ & $\begin{array}{l}\text { ABC-type bacteriocin transporter family } \\
\text { protein }\end{array}$ & $71 \%$, S. epidermidis plasmid SAP105A \\
\hline orf33 & $34541-35809$ & $\begin{array}{l}\text { DUF867 type protein, putative phage-related } \\
\text { protein }\end{array}$ & $\begin{array}{l}\text { 71\% (partially from position 35252), } \\
\text { S. epidermidis ATCC } 12228\end{array}$ \\
\hline ISShat & $37543-36061$ & ISShal & 98\%, S. haemolyticus JCSC1435 \\
\hline$c h r$ & $38832-37669$ & Chromate transporter & $\begin{array}{l}\text { 66\% (partially from position } 37895 \\
\text { to 38782), Oceanobacillus iheyensis HTE831 }\end{array}$ \\
\hline $\operatorname{ars} C$ & $39261-38869$ & Arsenate reductase & $\begin{array}{l}\text { 97\%, S. aureus strains LGA251 } \\
\text { and } M 10 / 0061\end{array}$ \\
\hline $\operatorname{ars} B$ & $40577-39279$ & Arsenical pump membrane protein & $92 \%$, S. xylosus plasmid pSX267 \\
\hline $\operatorname{ars} R$ & $40885-40571$ & Arsenical resistance operon repressor & $\begin{array}{l}91 \%, \text { S. aureus plasmid SAPO99B } \\
\text { and EDINA }\end{array}$ \\
\hline orf39 & $41223-41771$ & DUF576 type protein & $\begin{array}{l}\text { 100\%, S. haemolyticus JCSC1435 } \\
\text { (locus SH0120) }\end{array}$ \\
\hline orf40 & $41768-41935$ & Hypothetical protein & $\begin{array}{l}\text { 100\%, S. haemolyticus JCSC1435 } \\
\text { (locus SH0121) }\end{array}$ \\
\hline orf41 & $42126-43013$ & $\begin{array}{l}\text { Hypothetical protein, similar to } \\
\text { mechanosensitive ion channel Mscs, } \\
\text { transmembrane protein }\end{array}$ & $\begin{array}{l}\text { 100\%, S. haemolyticus JCSC1435 } \\
\text { (locus SH0122) }\end{array}$ \\
\hline orf42 & $43522-44046$ & DUF3267 type protein & $\begin{array}{l}\text { 100\%, S. haemolyticus JCSC } 1435 \\
\text { (locus SH0123) }\end{array}$ \\
\hline orf43 & $44998-44120$ & $\begin{array}{l}\text { Hypothetical protein, similar to cobalamin } \\
\text { synthesis related protein CobW }\end{array}$ & $\begin{array}{l}\text { 100\%, S. haemolyticus JCSC1435 } \\
\text { (locus SH0124) }\end{array}$ \\
\hline orf44 & $45625-46248$ & $\begin{array}{l}\text { Hypothetical protein, similar to Zn-binding } \\
\text { lipoprotein AdcA }\end{array}$ & $\begin{array}{l}\text { 100\%, S. haemolyticus JCSC } 1435 \\
\text { (locus SH0125) }\end{array}$ \\
\hline
\end{tabular}

\footnotetext{
${ }^{a}$ Positions are according to GenBank accession no. JQ764731.
}

${ }^{b}$ GenBank accession no.: S. aureus LGA251 (FR821779), S. aureus JCSC6943 (AB505628), S. aureus JCSC6945 (AB505630), S. aureus M10/0061 (FR823292), S. aureus MSHR1132 (FR821777), S. carnosus TM300 (AM295250), S. epidermidis ATCC 12228 (AE015929), S. epidermidis RP62a (CP000029), S. haemolyticus JCSC1435 (AP006716), S. saprophyticus ATCC 15305 (AP008934), Oceanobacillus iheyensis HTE831 (BA000028), S. aureus plasmid SAP099B (GQ900449), S. aureus plasmid EDINA (AP003089), S. epidermidis plasmid SAP105A (GQ900452), S. xylosus plasmid pSX267 (M80565).

'Closest matches of MGE (IS431 and ISSha1) and genes belonging to the mec complex are not listed as there are many identical matches.

${ }^{d}$ Truncated by IS431 with 19 bp of the $3 /$ end missing and the read frame extending into IS431.

${ }^{e}$ The tnpA of IS431 was terminated prematurely due to internal point mutation.

to orf39, part of the core chromosome of S. haemolyticus, designated IR3 here (Figure 1). This 40-kb region was actually bracketed by two IR, IR1 and IR3, resembling the remnant of a SCC-like element but without $c c r$ genes. In light of the presence of an internal IR, IR2, this $c c r$-absent large region was a remnant of a composite SCC element or comprised remnants of multiple SCC elements.

The $3.7-\mathrm{kb}$ region between orfX and the IS431-1 was designated R1 (representing region 1) and contained genes encoding ADP-ribosylglycohydrolase, permease and ribokinase. R1 was almost identical to the counterpart (loci SERP2216 to SERP2218) of the integrative plasmid $v \mathrm{Se} 1$ on the chromosome of $S$. epidermidis RP62a (GenBank accession no. CP000029) but was absent from S. haemolyticus JCSC1435, suggesting a foreign origin. Of note, the ribokinase-encoding gene, $r b k$, was truncated at the 3 / end by the insertion of IS431, leaving a 920 bp remnant of the 939 bp gene.

The region between the IS431-1 and IR2 was designated R2. As mentioned above, Tn6191 was inserted into the spacer between arsR and $\operatorname{cop} A$ in R2. Besides Tn6191, R2 also contained a few genes, the cadXD operon mediating resistance to cadmium and the ars operon required for detoxifying arsenate. In R2, the sequence from the IS431-1 to arsB was closest (99.9\% similarity) to the counterpart in the type IX SCCmec of S. aureus strain JCSC6943 (GenBank accession no. AB505628), while that from arsB to IR2 excluding Tn6191 was almost identical to the corresponding region in the type X SCCmec of $S$. aureus JCSC6945 (GenBank accession no. AB505630). This suggests that R2 might have resulted from homologous recombination between the ars operons of the type IX and 


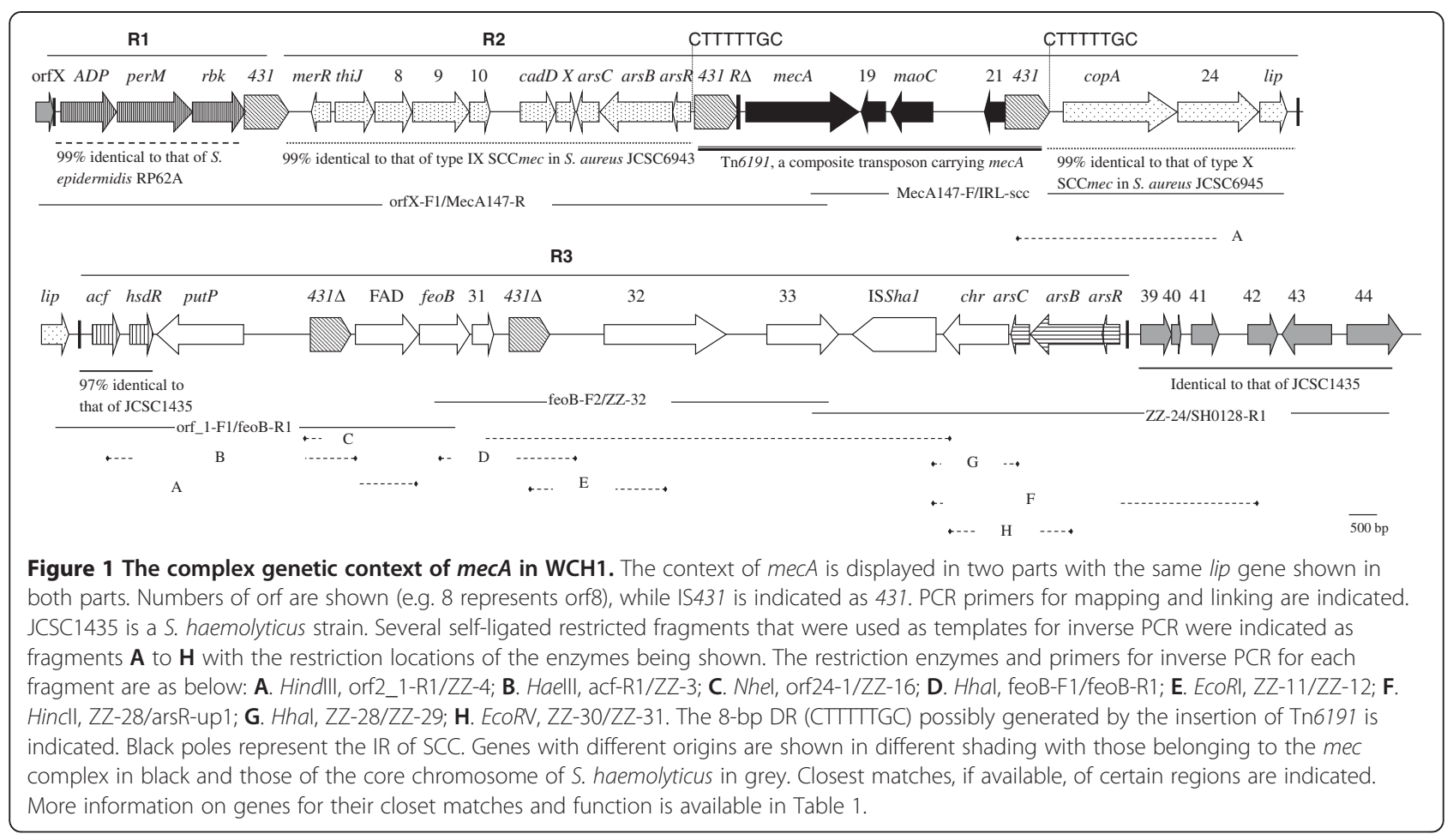

X SCCmec. R1 and R2 had different origins and were separated by a single copy of IS431, suggesting that IS431 served as a joining point that brought the two regions together.

The large region between IR2 and IR3 was designated R3. The two genes, acf and orf27 (putatively encoding a type I restriction endonuclease), adjacent to IR2 had 96.8\% identities to the counterparts of a SCC element on the chromosome of S. haemolyticus JCSC1435. At the other end of R3, there was a second copy of the ars operon, which was closest to those on a few S. aureus plasmids, e.g. pI258 (GenBank accession no. GQ900378) and pK59 (GenBank accession no. GQ900488) with 92.0\% identity and had only $86.4 \%$ identity with the first ars operon in $\mathrm{R} 2$ of $\mathrm{WCH} 1$. The intervening genetic components in $\mathrm{R} 3$ had lower than $80 \%$ identity with the closest matches identified by BLAST and were absent from the chromosome of S. haemolyticus JCSC1435. All above findings suggest that all genetic components in R3 had origins other than S. haemolyticus. Of note, there were two copies of IS431 and an ISSha1 in R3 but no DR could be identified, suggesting that these MGE were likely to have resulted from homologous recombination rather than direct insertion.

Of note, R3 contained several possible virulence factors. A putative proline permease-encoding putP gene was present on R3 and had 78\% identity with that of Staphylococcus saprophyticus strain ATCC 15305 [23]. putP has been identified as a virulence factor in $S$. aureus, contributing to invasive infection [24]. R3 also contained a $f e o B-$ like gene that was $68 \%$ identical to the counterpart of Staphylococcus carnosus strain TM300 (GenBank accession no. AM295250). feoB has been known as a virulence factor in Gram-negative bacteria, while its virulence status in Gram-positive remains controversial since it has been found conferring virulence in Streptococcus suis [25] but not in Listeria monocytogenesis [26] and there is no study of $f e o B$ for staphylococci. In addition, orf32 encodes a putative $A B C$-type bacteriocin transporter, which might involve in the regulation of virulence factor expression.

In addition, a number of genes encoding products for metabolism, transporting nutrients or detoxifying harmful substances were present in this large region carrying $m e c A$ (Table 1). The presence of these features could enhance the adaptation of the host strain to variable environment and therefore provided advantages in fitness. Of note, it has been reported that staphylococci are resistant to chromates [27]. A putative chromate transporter gene mediating resistance to chromates was found but with no significant matches in staphylococci. To our knowledge, it is the first time to identify a chromate transporter gene in staphylococci. It also suggests that additional mechanisms are responsible for the chromate resistance in staphylococci.

Although the genetic context of mecA was characterized in detail, the exact reason for the absence of $c c r$ genes in WCH1 remains undetermined. It is possible that $m e c A$ was originally carried by a SCCmec element with $c c r$ genes and the subsequent insertion of an additional IS431 upstream of mecA could give rise to the 
Table 2 Primers used for PCR

\begin{tabular}{|c|c|c|c|}
\hline Primer & Sequence $\left(5^{\prime}-3^{\prime}\right)^{a}$ & Target/location $^{b}$ & Reference \\
\hline acf-R1 & TCCTCAGCATCCTTTTCTTCA & acf & This study \\
\hline arsR-up1 & TGTGGATCTATGGAATTGAGGA & upstream of ars $R$ & This study \\
\hline feoB-F1 & ATGGTCTCCAAAAAGCATGA & $f e o B$ & This study \\
\hline feoB-F2 & AAGACAGGAACAAGCGAAACA & $f e o B$ & This study \\
\hline feoB-R1 & TGGGGCATTGATTACACTGA & $f e o B$ & This study \\
\hline IRL-SCC & TATCRGWTRATGATGMGGTTT & IRL of SCCmec & [7] \\
\hline 152 & TGAGGTTATTCAGATATTTCGATGT & 15431 & [31] \\
\hline MecA147-F & GTGAAGATATACCAAGTGATT & $\operatorname{mec} A$ & [30] \\
\hline MecA147-R & ATGCGCTATAGATTGAAAGGA & mecA & [30] \\
\hline orf_1-F1 & GAAATGAGCTGAAAGCACGA & lip & This study \\
\hline Orf2_1-R1 & TTGGAGGTTTCTCCCCATC & orf24, a Putative multicopper oxidases gene & This study \\
\hline Orf24-1 & CCAAATGAATTGTTAGACGTTG & spacer between putP and IS431 $\triangle$ & This study \\
\hline orfX-F1 & GAAAAAGCACCWGAAAMTATGAG & orf & {$[7]$} \\
\hline SH0128-R1 & TITGTGGTTGTGACGGTGT & orf45, locus SH0128 in AP006716 & This study \\
\hline ZZ-3 & GTGAGGTTGGTGGTGATAAAA & spacer between putP and IS431 $\triangle$ & This study \\
\hline $\mathrm{ZZ}-4$ & GCGGGTCCTTCTGGTATAGG & $F A D$ & This study \\
\hline ZZ-11 & TATCTCGGGAAATCGATAAAAA & spacer between IS431 and orf32 & This study \\
\hline ZZ-12 & GTTGAAAGGAAACAAAAACTACG & spacer between IS431 and orf32 & This study \\
\hline ZZ-16 & CCGATAACGTCATTCCATCT & orf32, ABC-type bacteriocin transporter gene & This study \\
\hline ZZ-24 & AGCACGACAACAAAAGCATC & orf33 & This study \\
\hline ZZ-28 & TGGAGGAGGAGTITGGCTA & orf35, chromate transporter & This study \\
\hline ZZ-29 & TACGACATGACCACCTCCAA & orf35, chromate transporter & This study \\
\hline ZZ-30 & GTAGCTGTTGCCATTGTTGC & orf35, chromate transporter & This study \\
\hline ZZ-31 & GCTTGCAGGTCCAGGTAAAA & orf35, chromate transporter & This study \\
\hline ZZ-32 & TGGACGTATCGCTTCAAATG & orf33 & This study \\
\hline
\end{tabular}

${ }^{a} \mathrm{D}: \mathrm{A}, \mathrm{G}$ or $\mathrm{T} ; \mathrm{H}: \mathrm{A}, \mathrm{C}$ or $\mathrm{T}: \mathrm{M}: \mathrm{A}$ or $\mathrm{C} ; \mathrm{R}: \mathrm{A}$ or $\mathrm{G} ; \mathrm{W}: \mathrm{A}$ or $\mathrm{T} ; \mathrm{Y}: \mathrm{C}$ or $\mathrm{T} ; \mathrm{V}: \mathrm{A}, \mathrm{C}$ or $\mathrm{G}$.

${ }^{b}$ More information about orfs listed here is available in Table 1.

potential composite transposon, Tn6191, together with the already-existed IS431 downstream of mecA. Tn6191 might have mobilized mecA into a new genomic location or alternatively, $\mathrm{Ccr}$ genes could have been deleted due to homologous recombination between multiple copies of IS431 that were present in WCH1.

\section{Conclusions}

$m e c A$ was identified in a 40-kb region that contained IR of SCC elements but no $c c r$ genes. This large region was very complex in structure and contained multiple genetic components with different origins. Genetic components with various origins were likely introduced in tandem by SCC elements and insertion sequences through insertion and homologous recombination. Two copies of IS431 bracketed mecA and were flanked the characteristic 8-bp direct repeat sequence, suggesting that the two IS431 might have form a composite transposon with the potential to be active. The IS431-formed composite transposon might represent a new mechanism for the mobilization of $m e c A$ independent of the action of SCCmec. The present study aimed to illustrating the complex context of mecA but further experiments to demonstrate the activity of Tn6191 in transposing mecA are warranted to confirm the proposed new mechanisms for the mobilization of mecA.

\section{Methods}

\section{Strain and SCCmec typing}

Clinical isolate WCH1 was recovered from blood collected in West China Hospital, Chengdu, western China, and was obtained as part of standard care. WCH1 was identified as $S$. haemolyticus by partially sequencing the $16 \mathrm{~S}$ rRNA gene amplified with the universal primers $27 \mathrm{~F}$ and 1492R [28]. WCH1 could grow on plates containing $4 \mu \mathrm{g} / \mathrm{ml}$ cefoxitin (Sigma, St Louis, MO). The MIC of cefoxitin against WCH1 was determined using the broth dilution method following the Clinical and Laboratory Standards Institute guidelines [29]. The $m e c A$ gene and its regulatory genes mecI and mecR 1 were detected by PCR [30]. The SCCmec typing was carried out using 
multiplex PCR [30]. The presence of $c c r$ genes were also examined by PCR using multiple universal primers as described previously [9].

\section{PCR mapping and inverse PCR}

Two overlapping long-range PCR (Fermentas, Burlington, $\mathrm{ON}$, Canada) were used to obtain two regions, one between $m e c A$ and orfX and the other between $m e c A$ and an inverted repeat (IR) sequence of SCC (Figure 1). A few inverse PCR reactions were employed to identify the genetic context of $m e c A$ with pairs of outwards-facing primers (Table 2 and Figure 1). Genomic DNA of WCH1 prepared using a commercial kit (Tiangen, Beijing, China) was restricted with a certain restriction enzyme (Figure 1), self-ligated with T4 DNA ligase (New England Biolabs, Ipswich, NY) and then used as a template for inverse PCR. The links between genetic elements were confirmed by overlapping long-range PCR (Figure 1, primers listed Table 2).

\section{Sequencing}

Amplicons were sequenced by primer walking using an ABI 3730xl DNA Analyzer (Applied Biosystems, Foster City, CA) at the Beijing Genomics Institute (Beijing, China). Sequences were assembled using the SeqMan II program in the Lasergene package (DNASTAR Inc, Madison, WI) and similarity searches were carried out using BLAST programs (http://www.ncbi.nlm.nih.gov/ BLAST/). The putative function of proteins was analyzed using the InterProScan tool (http://www.ebi.ac.uk/Tools/ $\mathrm{pfa} / \mathrm{iprscan} /$ ).

Nucleotide sequences accession number. The complete sequence of the genetic context of mecA in WCH1 has been deposited in GenBank as JQ764731.

\footnotetext{
Acknowledgments

This work was supported by a grant from the Project Sponsored by the Scientific Research Foundation for the Returned Overseas Chinese Scholars, State Education Ministry.

Part of this work has been presented (abstract number 1176) at the 22nd

European Congress of Clinical Microbiology and Infectious Diseases, March 31 to April 3, 2012, London, UK.

The author is grateful for Yanyu Gao for performing the susceptibility test.
}

Received: 19 September 2012 Accepted: 20 March 2013

Published: 22 March 2013

\section{References}

1. Hartman BJ, Tomasz A: Low-affinity penicillin-binding protein associated with $\beta$-lactam resistance in Staphylococcus aureus. J Bacteriol 1984 158:513-516.

2. Hanssen AM, Ericson Sollid JU: SCCmec in staphylococci: genes on the move. FEMS Immunol Med Microbiol 2006, 46:8-20

3. International Working Group on the Classification of Staphylococcal Cassette Chromosome Elements: Classification of staphylococcal cassette chromosome mec (SCCmec): guidelines for reporting novel SCCmec elements. Antimicrob Agents Chemother 2009, 53:4961-4967.

4. Hanssen AM, Sollid JU: Multiple staphylococcal cassette chromosomes and allelic variants of cassette chromosome recombinases in
Staphylococcus aureus and coagulase-negative staphylococci from Norway. Antimicrob Agents Chemother 2007, 51:1671-1677.

5. Berglund C, Soderquist B: The origin of a methicillin-resistant Staphylococcus aureus isolate at a neonatal ward in Sweden-possible horizontal transfer of a staphylococcal cassette chromosome mec between methicillin-resistant Staphylococcus haemolyticus and Staphylococcus aureus. Clin Microbiol Infect 2008, 14:1048-1056.

6. Ruppe E, Barbier F, Mesli Y, Maiga A, Cojocaru R, Benkhalfat M, Benchouk S, Hassaine H, Maiga I, Diallo A, et al: Diversity of staphylococcal cassette chromosome mec structures in methicillin-resistant Staphylococcus epidermidis and Staphylococcus haemolyticus strains among outpatients from four countries. Antimicrob Agents Chemother 2009, 53:442-449.

7. Zong Z, Lu X: Characterization of a new SCCmec element in Staphylococcus cohnii. PLoS One 2010, 5:e14016.

8. Takeuchi F, Watanabe S, Baba T, Yuzawa H, Ito T, Morimoto Y, Kuroda M, Cui L, Takahashi M, Ankai A, et al: Whole-genome sequencing of Staphylococcus haemolyticus uncovers the extreme plasticity of its genome and the evolution of human-colonizing staphylococcal species. J Bacteriol 2005, 187:7292-7308.

9. Zong Z, Peng C, Lu X: Diversity of SCCmec elements in methicillinresistant coagulase-negative staphylococci clinical isolates. PLoS One 2011, 6:e20191.

10. Chen L, Mediavilla JR, Smyth DS, Chavda KD, lonescu R, Roberts RB, Robinson DA, Kreiswirth BN: Identification of a novel transposon (Tn6072) and a truncated staphylococcal cassette chromosome mec element in methicillin-resistant Staphylococcus aureus ST239. Antimicrob Agents Chemother 2010, 54:3347-3354.

11. Oliveira DC, Tomasz A, de Lencastre H: The evolution of pandemic clones of methicillin-resistant Staphylococcus aureus: identification of two ancestral genetic backgrounds and the associated mec elements. Microb Drug Resist 2001, 7:349-361.

12. Dubin DT, Matthews PR, Chikramane SG, Stewart PR: Physical mapping of the mec region of an American methicillin-resistant Staphylococcus aureus strain. Antimicrob Agents Chemother 1991, 35:1661-1665.

13. Kobayashi N, Alam M, Urasawa S: Analysis on distribution of insertion sequence IS431 in clinical isolates of staphylococci. Diagn Microbiol Infect Dis 2001, 39:61-64.

14. Noto MJ, Fox PM, Archer GL: Spontaneous deletion of the methicillin resistance determinant, $m e c A$, partially compensates for the fitness cost associated with high-level vancomycin resistance in Staphylococcus aureus. Antimicrob Agents Chemother 2008, 52:1221-1229.

15. Wong H, Louie L, Lo RY, Simor AE: Characterization of Staphylococcus aureus isolates with a partial or complete absence of staphylococcal cassette chromosome elements. J Clin Microbiol 2010, 48:3525-3531.

16. Barberis-Maino L, Berger-Bachi B, Weber H, Beck WD, Kayser FH: IS431, a staphylococcal insertion sequence-like element related to IS26 from Proteus vulgaris. Gene 1987, 59:107-113.

17. Cohen S, Sweeney HM: Effect of the prophage and penicillinase plasmid of the recipient strain upon the transduction and the stability of methicillin resistance in Staphylococcus aureus. J Bacterio/ 1973, 116:803-811.

18. Cohen S, Sweeney HM: Transduction of methicillin resistance in Staphylococcus aureus dependent on an unusual specificity of the recipient strain. J Bacterio/ 1970, 104:1158-1167.

19. Cohen S, Sweeney HM, Basu SK: Mutations in prophage phi11 that impair the transducibility of their Staphylococcus aureus lysogens for methicillin resistance. J Bacteriol 1977, 129:237-245.

20. Kayser FH, Wust J, Santanam P: Genetic and molecular characterisation of resistance determinants in methicillin-resistant Staphylococcus-aureus. J Med Microbiol 1976, 9:137-148.

21. Trees $\mathrm{DL}$, landolo JJ: Identification of a Staphylococcus aureus transposon (Tn4291) that carries the methicillin resistance gene(s). J Bacteriol 1988, 170:149-154.

22. Bouchami $\mathrm{O}$, Ben Hassen $\mathrm{A}$, De Lencastre $\mathrm{H}$, Miragaia M: High prevalence of mec complex $\mathrm{C}$ and $\mathrm{ccrC}$ is independent of SCCmec type $\mathrm{V}$ in Staphylococcus haemolyticus. Eur J Clin Microbiol Infect Dis 2012 31:605-614.

23. Kuroda M, Yamashita A, Hirakawa H, Kumano M, Morikawa K, Higashide M, Maruyama A, Inose Y, Matoba K, Toh $H$, et al: Whole genome sequence of Staphylococcus saprophyticus reveals the pathogenesis of uncomplicated urinary tract infection. Proc Natl Acad Sci USA 2005, 102:13272-13277. 
24. Bayer AS, Coulter SN, Stover CK, Schwan WR: Impact of the high-affinity proline permease gene (putP) on the virulence of Staphylococcus aureus in experimental endocarditis. Infect Immun 1999, 67:740-744.

25. Aranda J, Cortes P, Garrido ME, Fittipaldi N, Llagostera M, Gottschalk M Barbe J: Contribution of the FeoB transporter to Streptococcus suis virulence. Int Microbiol 2009, 12:137-143.

26. Jin B, Newton SM, Shao Y, Jiang X, Charbit A, Klebba PE: Iron acquisition systems for ferric hydroxamates, haemin and haemoglobin in Listeria monocytogenes. Mol Microbiol 2006, 59:1185-1198.

27. Ug A, Ceylan O: Occurrence of resistance to antibiotics, metals, and plasmids in clinical strains of Staphylococcus spp. Arch Med Res 2003, 34:130-136.

28. Lane DJ: $16 S / 23 S$ rRNA sequencing. In Nucleic acid techniques in bacterial systematics. Stackebrant E, Goodfellow Mth edition. New York, NY: John Wiley \& Sons; 1991:115-175.

29. CLSI: Performance standards for antimicrobial susceptibility testing; twenty-first informational supplement. M100-S21. Wayne, PA, USA: Clinical and Laboratory Standards Institute; 2011.

30. Zhang K, McClure JA, Elsayed S, Louie T, Conly JM: Novel multiplex PCR assay for characterization and concomitant subtyping of staphylococcal cassette chromosome mec types I to V in methicillin-resistant Staphylococcus aureus. J Clin Microbiol 2005, 43:5026-5033.

31. Kondo $Y$, Ito $T, M a X X$, Watanabe $S$, Kreiswirth BN, Etienne J, Hiramatsu K: Combination of multiplex PCRs for staphylococcal cassette chromosome mec type assignment: rapid identification system for mec, ccr, and major differences in junkyard regions. Antimicrob Agents Chemother 2007, 51:264-274.

doi:10.1186/1471-2180-13-64

Cite this article as: Zong: Characterization of a complex context containing mecA but lacking genes encoding cassette chromosome recombinases in Staphylococcus haemolyticus. BMC Microbiology 2013 13:64.

\section{Submit your next manuscript to BioMed Central and take full advantage of:}

- Convenient online submission

- Thorough peer review

- No space constraints or color figure charges

- Immediate publication on acceptance

- Inclusion in PubMed, CAS, Scopus and Google Scholar

- Research which is freely available for redistribution 